\title{
THE TIMES AND SPACES OF LEADERSHIP DEVELOPMENT: (UN)DESIGNING LEARNING*
}

\author{
Pauline Fatien Diochon *** \\ Robert Garvep"s: \\ David Gray ${ }^{* * * * *}$
}

* doi:10.11144/Javeriana.cao31-57.ttsl. Reflection paper. Received: 01/11/2018. Accepted: 14/11/2018. Cite as: Fatien Diochon, P., Garvey, R., \& Gray, D. (2018). The times and spaces of leadership development: (un)designing learning. Cuadernos de Administración, 31(57), 5-17. http://dx.doi.org/10.11144/Javeriana. cao31-57.ttsl

** Pontificia Universidad Javeriana. ORCID: 0000-0001-7255-5361. E-mail: Fatien.pauline@javeriana.edu.co

*** York St John University. E-mail: r.garvey@yorksj.ac.uk

**** University of Greenwich, London. E-mail: D.E.Gray@greenwich.ac.uk 

"The impetus which enables you to fly is our great human possession. Everybody has it. It is a feeling of the connection one has with every source of power. But it is frightening! It is devilishly dangerous! That is why the majority of people are so willing to renounce any idea of flying and prefer to stroll quietly along the pavement and obey the law."

(Demian, Hermann Hesse, 2008)

\section{Introduction}

The above quotation taps into something within the human condition that is potentially at least, very powerful. We, human beings, have aspirations; flying might be just one of them! But the central point here is that "the majority of people" often comply or silence their aspirations. In some contexts around the world, silence and compliance could be seen as the "rational" choice. However, even within great oppressive regimes, the human spirit may shine through, and empowerment can potentially emerge.

Our complex and dangerous times set the context for both tragedy and hope. Against this backdrop, this special issue of Cuadernos de Administracion explores the ways in which leadership spirit can develop. To be more specific, we delve into this tension between tragedy and hope through the four following main themes:

- The spaces for learning

- Crossing boundaries for learning

- Timing in learning

- Power dynamics in learning spaces

\section{The spaces for learning}

Spaces for learning range from the political and economic contexts to the classroom setting.

In terms of the former, it is tragic that the global economy creates huge inequalities between nations and peoples within nations. The overarching learning space here is influenced by neofeudalism (Shearing, 2001). This is a context where much power over many people is accumulated in the hands of the few. This can mean that millions of people experience the pressures of globalized capitalism as relentless claims to work harder, 
to be more narrowly specialized, to be more vulnerable economically and to experience work as if it were emptied of all moral significance. Millions of workers experience the future as an uncertain threat (Sennett, 1998). Here, learning can be a means of escape, or simply a vehicle of further subjugation as people learn to comply. Escape, in the sense that learning itself can provide hope and an inner sense of confidence. It can enable people to step out of their situation and move on to new opportunities. But, in contrast, learning, delivered as "training" within traditional settings where the trainer has an expectation of compliance to pre-established "learning outcomes" that simply engineer what has been pre-specified is the potential road to subjugation (Bernstein, 1971).

It is not just globalized capitalism that creates oppression. In the paper in this Special Edition "Challenging the oppressive social context by redesigning learning space. The case of a business ethics class in Russia", Kalnitskaya informs us that the political environment, in this case, an oppressive regime, directly influences the learner's ability to interact with the subject matter, offer independent opinion or even be able to challenge one's assumptions. The only certainty here is that of silence or compliance. Yet, Kalnitskaya also offers hope, hope of improvement through innovative practices within the learning space and by adapting established ideas of, for example, narrative therapy and to apply them in new and different contexts. Similarly, in the paper "Aristotelian phronesis as a key factor for leadership in the knowledge-creating company according to Ikujiro Nonaka" by Scalzo and Fariñas, we find not only established ideas being employed to explore leadership development but we also see a combining of the Ancient Greek and Ancient Japanese philosophies to help throw new light on the spaces and vehicles for learning.

Now if we turn to traditional organizational learning settings, they mostly operate as inclass trainings where knowledge is transferred from one who "knows" to mostly passive recipients. Such designs portray learning as essentially individual, cognitive and a-contextual. This approach says nothing about emotional development or the development of values within any given context. It is a linear approach to learning where the outcome is pre-specified. Whilst this approach offers both accountability and quality control, it is, however, this emphasis on the outcome that excludes the notion of "learning as an ongoing process" and denies the relational, contextual, emotional and moral aspects of learning. As raised earlier, according to Habermas (1974), it creates a "hegemony of technique" which simply engineers the achievement of the pre-specified outcomes (Bernstein, 1971). Of course, this approach can help people to achieve with the pre-specified limits but, the processes of learning are unique to individuals, the contexts and 
spaces where the learning is employed are variable, dynamic and ever changing. It is unlikely that such an approach will develop such flexibility, nor develop people who are capable of innovation, creativity, improvisation, critical thinking, collaboration, social and emotionally awareness, change or a moral capacity and a tolerance of complexity. These are however some of the widely agreed attributes of modern leaders (Boyatzis \& Ratti, 2009; Burnison, 2012; Jackson \& Parry, 2011; Kouzes \& Posner, 2012; Yukl, 2013).

Hamlin et al. (2016) emphasise the contextual and subjective nature of learning in any given business context and it is particularly interesting to note that some (Batool, 2013; Mayer et al., 2001; Salovey \& Mayer, 1990) suggest that the abilities outlined in the previous paragraph are not acquired in the traditional training room but rather over periods of time through experience. It is here that more individualized and situationally significant (Lave \& Wenger, 1991) approaches to learning become important. Such approaches include coaching, mentoring and action learning, and take into account the individual, their context and the groups they work with. It is also here that online approaches, which may be drawn down at any time convenient to the learner, come into their own together with concepts such as critical reflection, reflexivity and mindfulness come into the mix of the learning space.

The paper "This is not a cake recipe: historicity as an element for the understanding and transformation of a waste management activity at a university hospital in Brazil" by Rodrigues Paniza and Cassandre explores the creation of an authentic learning space to investigate a problem and develop a new future by employing a situated, contextually specific and dialogic learning process to access the collective memory within an organization. Here, the workplace is the learning space and the learning is fundamentally a social process whereby the learners learn by, with and through each other (Garvey, 2011). This approach confirms Vygotsky's (1978) view that "social transaction is the fundamental vehicle of education and not, so to speak, solo performance" (Bruner, 1985, p. 25).

In a similar vein, advocating for a "politics of space" Jørgensen depicts how organizations shape people. The author indeed demonstrates how the "arrangement of space enacts people in organizations in such a way that their thinking, actions and judgments become produced by organizations instead of produced by themselves". Jørgensen therefore calls for "a political approach to leadership and its development", with the definition leadership as "the collective actions in which unique subjects, who can think, act and judge for themselves, are engaged". Here Jørgensen wants to emphasize the "collective, relational and material aspects" of leadership, and its development. 
There is a moral dimension within all the above not least because as Jarvis (1992, p. 7) argues "learning, and perhaps knowledge itself, has significant moral connotations". He links his argument to the biblical story of Adam and Eve. Both were innocent until they ate of the tree and then they became aware of both good and evil. There are some theologians who refer to this symbolic act as "the fall". However, Archbishop William Temple offered a counter view by suggesting that it was a fall upwards in that it is this that created the greatest paradox of all human learning - the fact that learning, which is generally regarded as 'good' is symbolically associated with origin evil in the world! Kalnitskaya's attempts to tackle this issue are to be applauded in helping learners to become critical thinkers and moral practitioners (Cunliffe, 2004) and central to her work is the development of reflexivity, a potential source of ethical practice in coaching (Fatien Diochon \& Nizet, 2015).

In sum, it is clear that the situations and contexts of learning spaces can be both emancipatory and oppressive (Louis \& Fatien Diochon, 2018). However, the human spirit and desire to metaphorically 'fly' finds ways to overcome the oppression and it is also paradoxically important to note that these restrictions and oppressions may be the very source of new learning. History has taught us that out of adversity, there can sometimes emerge new thoughts and new ways. These may come from a reconceptualization of older ideas (as some of our papers highlight) but learning to solve such challenges can also take on new forms. There is always the possibility to fly!

\section{Crossing boundaries for learning}

As these new learning spaces develop, the cultural and inter-cultural boundaries shift. Global and fast communication has made it possible for people to interact with each other, to work towards understanding each other in new ways. It is possible to talk with someone across the globe in an instant. The opportunity this offers for building new relationships is immense. With this, of course, comes a new requirement for learning. Learning to tolerate, learning to accept difference and to see these culture differences as potentials not hindrances. With this also come challenges. Globalization, in some cases has become the new colonialization and with this comes the expectation of compliance to international standards. Often these take no account of local differences of:

- The economic context

- The philosophical underpinning

- Technology 
- The legal context

- The political climate

- Sociological and cultural issues (Garvey et al., 2017)

The presence of these factors in any particular region are likely to influence how learning and development is accessed and valued. For example, Kalnitskaya questions the applicability of Western approaches to education being applied within an oppressive and economically sparse regime. She argues that in oppressive societies,

traditional methods of education do not only prove ineffective, but also become part of the oppressive system. Practical focus on improvement within the boundaries of a social system reinforces the dominant culture and distracts from a critical look towards the whole system. (Habermas, 1970; Marcuse, 1991; Shoukry, 2016)

However, within more developed economies, the drives towards a utility-based curriculum is relentless. The economic mind-set of "reduce cost" means that courses become shorter and, as raised earlier, outcome focused. The underpinning philosophy of, for example, blue sky learning, or learning for its own sake, in line with a humanist philosophy which celebrates the wonder of being a learning human being, or a more open ended approach, is giving way to a functional approach. Barnett (1994) refers to this as "strategic reasoning", and he argues that "Society is more rational, but it is a rationality of a limited kind" (p. 37) and that "genuinely interactive and collaborative forms of reasoning" (p. 32) are being driven out by 'strategic reasoning. The "strategic reasoning" philosophy creates a utility-based education.

Additionally, what is lawful in one country may not be in another. The legal context can, for example, defend free speech or it can curtail it. Here learners may not be able to freely engage. Further, what is socially acceptable in any given place, attitudes towards time status, age, gender, for example, may make boundary crossing challenging.

Interestingly, Scalzo and Fariñas have taken seriously this challenge of crossing boundaries in learning by referring to the work of the Japanese scholar Ikujiro Nanaka, who combine a Western classical tradition (the virtue of phronesis) with the Japanese notion of $B a$ (context-based learning). Now bridging Europe and Latin America, the article by Rodrigues Paniza and Cassandre brings to the Brazilian context the work of the Belarusian Vygotsky (1978). 
Finally, a different kind of social context for learning or potentially "boundary free" approach not covered by any papers in this edition but, an important and growing area, is technology. Increasingly, people are employing electronic media to make social connections and to offer new spaces for learning. There are an exponentially increase plethora of modes of communication emerging to, in some cases, compliment more traditional approaches and in others, to completely replace them. Applications such as Skype, WhatsApp, Messenger and Zoom for example, provide alternatives to conventional ways of people meeting for whatever purpose (this editorial was written through discussions on Zoom). Whilst technology has offered the potential for a new form of emancipation, within some countries there are determined efforts to control technology, with, for example, some governments seeking to block certain social media networks and learning platforms in order to maintain the status quo. Yet, human ingenuity is capable of thinking around these issues and finding a way forward.

In general, globalized neofeudalism seeks compliance; but how far this is possible across international boundaries is debatable. What is clear is that individuals will create and develop ways to cross these boundaries and to reach out to others and whilst huge global inequalities exist, these individuals provide a new hope that things could be different. Technology may hold the key.

\section{Timing in learning}

Within learning theories as applied to work based learning, there are certain dominating discourses. One such discourse is "competitiveness". It is within the "competitiveness" discourse that timing takes on a new urgency.

Learning has to be fast and timely, and according to Arnaud (2003, p. 1132), this has led to a working culture in many organizations that this is "more bitter, individualistic and prevalent in the workplace now than ever before". Arnaud (2003, p. 1132) argues that the increased pressure to perform and develop individual employability in a context of poor job security leads to the need for "personalized counselling, both on the part of those most directly concerned ... and on the part of the heads of organizations and top executives". Here practices like coaching and mentoring may have something to offer as a more acceptable form of therapy (Grant, 2007) on one hand but as a way of supporting people to slow down and savor the journey of learning away from the fast moving day to day activities (Megginson \& Boydell, 1979). The approaches to learning 
and time in all the papers in this edition represent similar human processes of slowing down, exploring narratives and engaging in conversations. For example, Rodrigues Paniza and Cassandre show how organizational collective memory builds the present, and how historicity is present in the experiences lived by the workers, allowing self-awareness, and recognition of the value of one's work. It is possible to speculate that behind these papers rests the idea that "things could be different", that people are crying out for things to be different in this complex and dangerous world we have allowed to emerge.

Another discourse involving timing is that of efficiency inherent within the concept of "managerialism". The managerialist discourse is about cause and effect thinking, objectivity, one best way and "rational pragmatism" (Garvey \& Williamson, 2002). Bauman (1989, p. 103) argues that the managerialist discourse positions people so that they become "Reduced, like all other objects of bureaucratic management, to pure, quality-free measurements, human objects lose their distinctiveness. They are already dehumanized ... It is difficult to perceive and remember the human behind ... technical terms". As discussed above, this is a moral issue. It is, however, also a way of thinking about the pragmatics of learning.

Many adult learning theories are positioned within some sort of time line. This suggests that the learner moves through various stages or phases, in relation to time. This assumption leads to the creation of a training plan or corporate curriculum (Garvey \& Williamson, 2002) within a specific time line. It also creates "levels" of learning from the basic to the advanced for example, as well as reductionist competency frameworks against which people are assessed into successes and failures. This managerialist way of organizing learning has various practical benefits of structure and a sense of progress against a time line but, how far is this adequate for guiding learners within this complex, intercultural and global world where uncertainty is the only certainty!

Barnett (1994, p. 73) comments that: "the notion of competence is concerned with predictable behaviours in predicable situations"; our current world is anything but predictable and therefore teaching and learning needs to change to reflect these change circumstances. What was seen as "necessary to know" in the past, now takes on a different meaning. Consequently, the timing of learning could develop into something that is less taught against certain stages of phases and more developmental in relation to context and purpose along the lines suggested by Knowles (1984) where he argues that adult learners learn: 
- based on the adult's need to know

- on the adult's experience, involving, shared and participative, relevant and applied, problem-centered learning rather than content-oriented

- driven by the individual's internal motivations rather than external motivators

In this regard, Scalzo and Fariñas, by referring to the concept of $B a$, points out the situated, episodic, emergent and non-linear dimension of learning, with knowledge "created at a specific moment and circumstances, in the 'here and now".

\section{Power dynamics in learning spaces}

Returning to the idea of "neofeudalism", here, life and work is driven by rules and an assumption from those that are in power positions, of compliance and therefore, control. This control is not just of trade and raw materials; it extends to intellectual capital, knowledge and ideas and the means to control their dissemination. In the case of management, the modern workplace seeks control through surveillance processes to extract compliance i.e. appraisal and Personal Development Reviews, performance management, 360 appraisal and perhaps coaching and mentoring (Nielsen \& Nørreklit, 2009; Garvey, 2014). This is well depicted in Jørgensen's paper discussing the phenomenon of organizational "subjectification". The space for learning in this organizational context is thus controlled and restricted. And, as mentioned above, the traditional approach to learning in the workplace has revolved around training events. This model is inherently a power based model. Power here is held by the trainer who "knows". This is an alluring model and one that disempowers people and keeps them in their "place". The theories of learning have similar embedded assumptions of content and progress, assessors and receivers. The metaphor of "flying" introduced at the start of this piece breaks down when those with power clip people's wings!

A key challenge here is the question of "whose agenda is being played out?" when approaches to leadership development are considered. All contributors to this edition imply that when the learning agenda is more with the learner, power is returned to those who do the learning, but the question of power in learning spaces becomes inescapable. For example, Jørgensen introduces the idea of organizations as potential "infrastructure of becoming" when proper designs allow individuals to think, act and judge for themselves. In similar veins, Habermas (1989) argued that it is not possible for there to be a truly open conversation if there is a sense of power between the discussants. His alternative was the "ideal speech" situation. In theory at least, the ideal speech situation can be 
nurtured between people who have the same information or knowledge on a topic, the same skills to discuss it and they also agree beforehand the boundaries of the discussion and to respect one another. How far this is truly possible to achieve within work settings is open to question and Habermas (1989) suggests that it is something to aspire to in order to create the best conditions possible for an open discussion in the learning space.

It is against this complex background embracing the tragedy-hope tension inherent to our social, political, cultural, organizational contexts that learning spaces of leadership development need to be redesigned. Jarvis' book title "Paradoxes of Learning: On Becoming an Individual in Society" (1992) truly represents the paradox between tragedy and hope within a learning society and provides the backdrop to this collection of papers.

\section{References}

Arnaud, G. (2003). A coach or a couch? A Lacanian perspective on executive coaching and Consulting. Human Relations, 56(9), 1131-1154.

Barnett, R. (1994). The Limits of Competence. London: Open University Press and Society for Research into Higher Education.

Batool, B. F. (2013). Emotional intelligence and effective leadership. Journal of Business Studies Quarterly, 4(3), 84-94.

Bauman, Z. (1989). Modernity and the Holocaust. Cambridge: Polity.

Bernstein, B. (1971). On the Classification and Framing of Educational Knowledge. In Young, M. F. (ed.), Knowledge and Control: New Directions for the Sociology of Education (pp. 4769). London: Open University, Collier-MacMillan.

Boyatzis, R., \& Ratti, F. (2009). Emotional, social and cognitive intelligence competencies distinguishing effective Italian managers and leaders in a private company and cooperatives. Journal of Management Development, 28(9), 821-838.

Bruner, J. (1985). Vygotsky: A historical and conceptual perspective. In Wertsch, J. V. Culture,

Communication and Cognition: Vygotskian perspectives. Cambridge, London and N.Y.: Cambridge University Press.

Burnison, G. (2012). The twelve absolutes of leadership. New York: McGraw-Hill.

Cunliffe, A. (2004). On becoming a critically reflexive practitioner. Journal of Management Education, 28(4), 407-426.

Fatien Diochon, P., \& Nizet, J. (2015). Ethical Codes and Executive Coaches: One size does not fit all. Journal of Applied Behavioral Science, 51(2), 277-301.

Garvey, B. (2014). Neofeudalsim, Surveillance and Supervision. e-Organisations \& People, 21(4), 41-49. 
Garvey, B., \& Williamson, B. (2002). Beyond Knowledge Management: Dialogue, Creativity and the Corporate Curriculum. Harlow: Pearson Education.

Garvey, B., Stokes, P., \& Megginson, D. (2017). Coaching and mentoring theory and practice, $3^{\text {rd }}$ ed., London: Sage Publication.

Garvey, B. (2011). A very short, slightly interesting and reasonably cheap book on Coaching and Mentoring. London, UK: Sage Publication.

Grant, A. M. (2007). Enhancing coaching skills and emotional intelligence through training. Industrial and Commercial Training, 39(5), 257-266.

Habermas, J. (1970). Technology and science as "ideology". In Shapiro, J. (ed.), Toward a Rational Society: Student protest, science, and politics. Boston: Beacon Press.

Habermas, J. (1974). Theory and Practice. London, UK: Heineman.

Habermas, J. (1989). The Theory of Communicative Competence: The Critique of Functionalist Reason, 2. Cambridge, UK: Polity.

Hamlin, R., Kim, S., Chai, D., Kim, J., \& Jeong, S. (2016). Perceived managerial and leadership effectiveness within South Korean and British private companies: a derived etic comparative study. Human Resource Development Quarterly, 27(2), 237-269.

Jackson, B., \& Parry, K. (2011). A very short, fairly interesting and reasonably cheap book about studying leadership, $2^{\text {nd }}$ ed., London: Sage Publication.

Jarvis, P. (1992). Paradoxes of Learning: On Becoming an Individual in Society. San Francisco, CA: Jossey-Bass Higher Education Series.

Jørgensen, K., \& Fatien Diochon, P. (2018). Creative coaching in the organizational space of appearance. Paper presented at the LAEMOS Conference, Buenos Aires, 22-24 March.

Knowles, M. (1984) Andragogy in Action. San Francisco: Jossey-Bass.

Kouzes, J. M., \& Posner, B. S. (2012). The leadership challenge, how to make extraordinary things happen in organisations, $5^{\text {th }}$ ed. San Francisco: Jossey-Bass.

Lave, J., \& Wenger, E. (1991). Situated Learning: Legitimate Peripheral Participation. Cambridge: Cambridge University Press.

Louis, D., \& Fatien Diochon, P. (2018). The coaching space: A production of power relationships in organizational settings. Organization, 25(6), 710-731.

Marcuse, H. (1991). One-dimensional man: studies in the ideology of advanced industrial society, $2^{\text {nd }}$ ed. Boston: Beacon Press.

Mayer, J., Salovey, P., Caruso, D., \& Sitarenios, G. (2001). Emotional intelligence as a standard intelligence. Emotions, 1(3), 232-242.

Megginson, D., \& Boydell, T. (1979). A Manager's Guide to Coaching. London: BACIE.

Nielsen, A., \& Nørreklit, H. (2009). A discourse analysis of the disciplinary power of management coaching. Society and Business Review, 4(3), 202-214. 
Salovey, P., \& Mayer, J. (1990). Emotional intelligence. Imagination, Cognition and Personality, 9(3), 185-211.

Sennett, R. (1998). The Corrosion of Character: the Personal Consequences of work in the New Capitalism. New York: W.W. Norton and Company.

Shearing, C. (2001). Punishment and the Changing Face of the Governance. Punishment \& Society, 3(2), 203-220.

Shoukry, H. (2016). Coaching for emancipation: A framework for coaching in oppressive environments. International Journal of Evidence Based Coaching and Mentoring, 14(2), 15-30.

Vygotsky, L. (1978). Interaction between learning and development. In: Cole, M. et al. Mind in society (pp. 79-91). Cambridge: Cambridge University Press.

Yukl, G. (2013). Leadership in organisations, 8th ed. Essex: Pearson Education Ltd.

Licencia Creative Commons CC BY 4.0 
